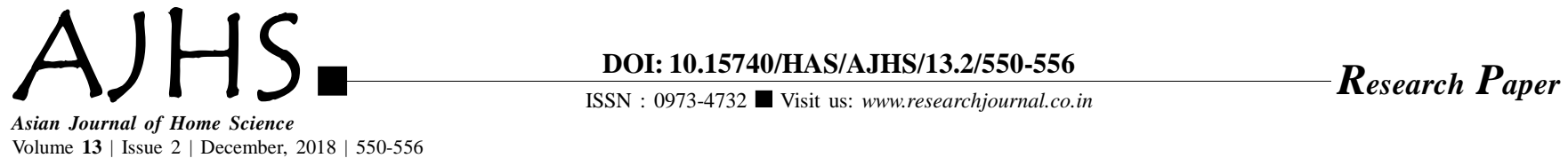

\title{
Readability and comprehension of distance education package on nutrition and value addition for rural women
}

Nisha Tiwari

Author for correspondence :

\section{Nisha Tiwari}

Krishi Vigyan Kendra, Gumla (Jharkhand) India

Email : umnish@yahoo.co.in; nishakvkgumla@gmail.com
Received: 10.05.2018; Revised: 22.10.2018; Accepted: 05.11 .2018

ABSTRACT : The study was conducted in purposively selected two villages Kolayat and Jhajhu of Kolayat Panchayat Samiti of Bikaner district, Rajasthan. Fifty rural women (fifth class onwards) were selected randomly ( 25 from each village) by chit method. Pre and post experimental research design was used for present study. The overall readability of the Module I was found to be very good as the mean score obtained by respondents for overall readability of Module I (22.7) closer to maximum scores (score range 16-25) and overall readability of the Module II was found to be very good as the mean score obtained by respondents for overall readability of Module II (23.6) closer to maximum scores (score range 18-27). In Module I majority of the respondents $(70 \%)$ were above mean scores while only 30 per cent respondents were below mean score and in Module II majority of the respondents (80\%) were above mean scores while only 20 per cent respondents were below mean score. For overall comprehension of Module I obtained 35.85, from total score range (score range 26-38). The overall comprehension of Module I in terms of the title, key messages and illustrations was excellent as majority of the respondents (86\%) were above mean score followed by below mean score $(14 \%)$ and for overall comprehension of Module II obtained 45, from total score range (32-49). The overall comprehension of Module II in terms of the title, key messages, and illustrations was excellent as majority of the respondents $(705 \%)$ were above mean score followed by below mean score 30 per cent.

KEY WORDS: Distance education package, Nutrition, Value addition, Readability, Comprehension

- HOW TO CITE THIS PAPER : Tiwari, Nisha (2018). Readability and comprehension of distance education package on nutrition and value addition for rural women. Asian J. Home Sci., 13 (2) : 550-556, DOI: 10.15740/HAS/AJHS/13.2/550-556. Copyright@ 2018: Hind Agri-Horticultural Society. 